\title{
Development of a quality control material for the analysis of volatile compounds in alcoholic beverages
}

\author{
Siarhei Charapitsa ${ }^{*}$, Svetlana Sytova ${ }^{1}$, Anton Kavalenka ${ }^{1}$, \\ Lidia Sobolenko ${ }^{1,2}$, Yauheni Shauchenka ${ }^{1}$, Nikolai Kostyuk ${ }^{2}$, \\ MikhailZayats ${ }^{2}$,VladimirEgorov ${ }^{2}$,SergeyLeschev ${ }^{2}$, \\ Ina Melsitova ${ }^{2}$, Siarhei Vetokhin ${ }^{3}$ and Natalia Zayats ${ }^{3}$ \\ ${ }^{1}$ Institute for Nuclear Problems of Belarusian State University, Bobruyskaya Str., 11, Minsk, \\ Belarus, 220030 \\ ${ }^{2}$ Belarusian State University, Nezavisimosti Av., 14, Minsk, Belarus, 220030 \\ ${ }^{3}$ Belarusian State Technological University, Sverdlova Str., 13a, Minsk, Belarus, 220006
}

(Received November 10, 2021; Revised December 16, 2021; Accepted December 17, 2021)

\begin{abstract}
A quality control material (QCM) for the analysis of volatile compounds in alcoholic beverages was developed. The problems of the development and production of QCM were investigated. The seven water-ethanol solutions, containing 9 volatile compounds (acetaldehyde, methyl acetate, ethyl acetate, methanol, propan-1-ol, propan-2-ol, 2-methylpropan-1-ol, butan-1-ol and 3-methylbutan-1-ol) with a concentration range from 1.20 to 5000 $\mathrm{mg} / \mathrm{L}$ of anhydrous ethanol were prepared and studied according to the ISO Guide 80 and ISO Guide 35 in order to prove their stability over 6 months. The algorithm for the assessment of uncertainty associated with the characterization of QCM was developed. The studies were carried out by validated direct gas chromatography (GC) method with flame ionization detection (FID), based on using ethanol as an internal standard. The expanded relative uncertainty of QCM does not exceed $4.5 \%$.
\end{abstract}

Keywords:Quality control material (QCM); homogeneity assessment; stability assessment; alcoholic beverages; volatile compounds; uncertainty estimation. (C) 2021 ACG Publications. All rights reserved.

\section{Introduction}

The certified reference material (CRM) is one of the important instruments in analytical chemistry for validation of analysis methods and assessment of the trueness of the results, obtained in analysis [1]. Review of offers of RM and CRM for analysis of alcoholic beverages showed, that there are two main manufacturers of such products - LGC Standards and Sigma-Aldrich. These RM and CRM largely are 1) the water-ethanol mixtures with exact value of concentration of ethanol for determining of strength of alcoholic beverage(wine, beer, lager, brandy and whiskey)[2]; 2) matrix whiskey material (Certified Reference Material LGC5100 Whisky-Congeners) [3], which contains 6 volatile compounds: methanol, propan-1-ol, 2-methylpropan-1-ol, butan-1-ol, 2-methylbutan-1-ol and 3-methylbutan-1-ol and presents

*Corresponding author E-Mail: siarhei.charapitsa@gmail.com 
only one level of concentration.Thus, there are currently no proposals of RM and CRM for determination of mass concentrations of volatile compounds in wide range of alcoholic beverages (except whiskey).

The quality control material (QCM), variously referred to in the literature as "in-house reference material", can partially perform CRM and RM functions in terms of an assessment of repeatability, intermediate precision and reproducibility [4].

For this reason, the water-ethanol solutions with 9 volatile compounds (acetaldehyde, methyl acetate, ethyl acetate, methanol, propan-1-ol, propan-2-ol, butan-1-ol, 2-methylpropan-1-ol and 3methylbutan-1-ol) were proposed as quality control material (QCM). The choice of 9 of these volatile compounds is due to the fact that they are the most researched for the method in previous studies [5-8], and also the most frequently analyzed volatile compounds of alcoholic products.

The developed QCM are the water-ethanol solutions with ethanol volume concentration (40 \pm 0.1$) \%$ alcohol by volume (ABV) and with volatile compounds in concentration range from 1.20 to $5000 \mathrm{mg} / \mathrm{L}$ of AA (absolute alcohol - AA). The measurement method was GC-FID modified internal standard method, based on ethanol usage as an internal standard [5]. The results of assessment of metrological characteristics of the method in single-laboratory and interlaboratory studies were performed in previous works $[7,8]$. The statistical insignificance of influence of the matrix effect on the results obtained by the developed method has been proved [9]. This allows the use of calibration characteristics (relative response factors of the detector to the volatile compound relative to ethanol) obtained for waterethanol standard solutions for analysis of wide range of alcoholic beverages (bourbon, brandy, calvados, gin, grappa, rakia, rum, tequila, sake, scotch, vodka, whiskey, wine, liquor) and rectified ethyl alcohol [10].

At the present time, the official method for determination of volatile compounds in alcoholic beverages, used in the vast majority of countries in the world, for example, EU [11], USA [12], China [13], India [14], Mexico [15] and etc., include a procedure for preparing solutions for calibration, checking detector response linearity and quality control of obtained results. These solutions consist of ethanol (40 $\% \mathrm{ABV}$ ), water and volatile compounds with concentration range from 10 to $1000 \mathrm{mg} / \mathrm{L}$ of AA approximately [1]. The reagent of ethyl alcohol $96 \% \mathrm{ABV}$ is used for preparation of base water-ethanol solution for further preparation of standard solutions according to the official method. It is necessary to notice, that this reagent, as rule, contains acetaldehyde, methanol and propan-2-ol, which is difficult to fully separate from ethyl alcohol with inexpensive methods. Thus, it is necessary to take into account the concentrations of these impurities in order to obtain more accurate results. This problem was taken into account and resolved for developed QCM.

The range of volatile compounds' concentrations from 1.20 to $10 \mathrm{mg} / \mathrm{L}$ AA was added in order to make more accurate analysis of vodka, gin and rectified ethyl alcohol. The results of previous studies of spirit drinks and ethanol-containing products $[9,10]$ showed, that the minimal concentration levels of volatiles can be about $0.4 \mathrm{mg} / \mathrm{L} \mathrm{AA}$. This concentration value is higher than the limit of quantification (LOQ) of the method [10], but it is too difficult to obtain such limit with the required accuracy.For this reason,the concentration level about $1.2 \mathrm{mg} / \mathrm{L} \mathrm{AA}(0.5 \mathrm{mg} / \mathrm{L})$ was chosen as the lowest concentration point. The highest concentration point was approximately $5000 \mathrm{mg} / \mathrm{L} \mathrm{AA}(2000 \mathrm{mg} / \mathrm{L})$, since the results of studies $[9,10]$ showed, that the highest levels of volatiles' concentrations are often have values between 1000 and $5000 \mathrm{mg} / \mathrm{L} \mathrm{AA}$.

\section{Experimental}

\subsection{Materials and Methods}

High-purity ethanol with 96 \% ABV was supplied by Dyatlovo Distillery Plant "Algon" (Grodno, Belarus). Pure deionized water was purchased at JSC "Integral" (Minsk, Belarus). The following chemical standards were purchased from Sigma Aldrich (Madrid, Spain) with the highest purity available (more than $99.5 \%$ ): acetaldehyde, methyl acetate, ethyl acetate, methanol, propan-2-ol, propan-1-ol, 2methylpropan-1-ol, butan-1-ol, 3-methylbutan-1-ol.

All solutions were prepared gravimetrically according to the ASTM D4307 [16].

Water-ethanol solution (WES) with ethanol volume concentration $40 \% \mathrm{ABV}$ was prepared by mixing of high-purity ethanol with $96 \% \mathrm{ABV}$ and deionized water. 
Development of a quality control material for the analysis

The solution $A$ (with approximate concentrations of volatile compounds $5000 \mathrm{mg} / \mathrm{L} \mathrm{AA}$ ) was prepared by adding of the volatile compounds (acetaldehyde, methyl acetate, ethyl acetate, methanol, propan-2-ol, propan-1-ol, 2-methylpropan-1-ol, butan-1-ol, 3-methylbutan-1-ol) to WES.

The calibration solution $C^{*}$ (with approximate concentrations of volatile compounds $250 \mathrm{mg} / \mathrm{L}$ AA) was prepared by mixing of solution $A$ and $W E S$.

The solutions $B, C, D$ and $E$ (with approximate concentrations of volatile compounds 500; 250; 200; $25 \mathrm{mg} / \mathrm{L}$ AA, correspondingly) were prepared by mixing of solution $A$ and $W E S$.

The solutions $F$ and $G$ (with approximate concentrations of volatile compounds 10 and $1.2 \mathrm{mg} / \mathrm{L}$ AA, correspondingly) were prepared by mixing of solution $C$ and WES.

Since reagent ethanol, depending on its origin, often contains volatile compounds (as rule methanol, acetaldehyde, propan-2-ol, etc.), it was necessary to take account volatile compounds, which are present in WES(Figure 1). The algorithm for this calculation is presented in the item S.1 of Supplementary material. The mass concentrations and corresponding uncertainties of concentrations of prepared solutions are shown in Table S.1.2 of Supplementary material.

The experimental study was carried out in full accordance with ISO Guide 80 [4], ISO/IEC 17025 [17], ISO Guide 35 [18], ISO 17034 [19] and ISO 5725-2 [20].

\subsection{GC-FIDAnalysis Conditions}

Analysis was performed using a gas chromatograph Crystal-5000.1 (JSC SDB Chromatec, Yoshkar-Ola, Russia), equipped with the autosampler and FID detector. All the separations were carried out with a capillary column Rt-Wax, $60 \mathrm{~m} \times 0.53 \mathrm{~mm}, 1.0 \mu \mathrm{m}$ (Restek, Bellefonte, USA). The injections were made in the split mode (10:1), and the injection volume was $1.0 \mu \mathrm{L}$. The temperature of injector was $190^{\circ} \mathrm{C}$. The oven was programmed for $75^{\circ} \mathrm{C}$ for $9 \mathrm{~min}$, increased by $5^{\circ} / \mathrm{min}$ to $130^{\circ} \mathrm{C}$, then increased by $10^{\circ} / \mathrm{min}$ to $180^{\circ} \mathrm{C}$, followed by $5 \mathrm{~min}$ at the final temperature. The temperature of FID was $280^{\circ} \mathrm{C}$. All solutions were measured twice under repeatability conditions. The typical chromatograms of WES and solutions $A-G$ are shown in Figures 1 and 2.

\subsection{Calibration}

The single-point calibration method was performed every two weeks during the study with the usage of the calibration solution $C^{*}$. The values of $R R F_{i}^{E t h}$ (Relative Response Factor $-R R F$ ) for each volatile compound were determined according to the following formula [5-10]

$$
R R F_{i}^{E t h}=\frac{C_{i}^{C^{*}}}{A_{i}^{C^{* *}}} \cdot \frac{A_{E t h}^{C *}}{\rho_{E t h}},
$$

where $C_{i}^{C^{*}}$ is the concentration of the $i$-th volatile compound in the calibration solution $C^{*}$, expressed in $\mathrm{mg} / \mathrm{L}$ AA units; $A_{i}^{C^{*}}$ and $A_{E t h}^{C^{*}}$ are the detector responses for $i$-th volatile compound and ethanol in the calibration solution $C^{*}$, correspondingly, a.u. (arbitrary units), $\rho_{E t h}$ is the density of pure ethanol, $\rho_{E t h}=$ $789300 \mathrm{mg} / \mathrm{L}$.

\subsection{Concentration Calculations}

The experimental values of concentration of analytes $C_{i}^{k}$ was determined according to the following formula [5-10]

$$
C_{i}^{k}=R R F_{i}^{E t h} \frac{A_{i}^{k}}{A_{E t h}^{k}} \cdot \rho_{E t h},
$$

where $A_{i}^{k}$ and $A_{E t h}^{k}$ are the detector responses for $i$-th volatile compound and ethanol in the $k$-th studied solution (QCM), correspondingly, a.u. 


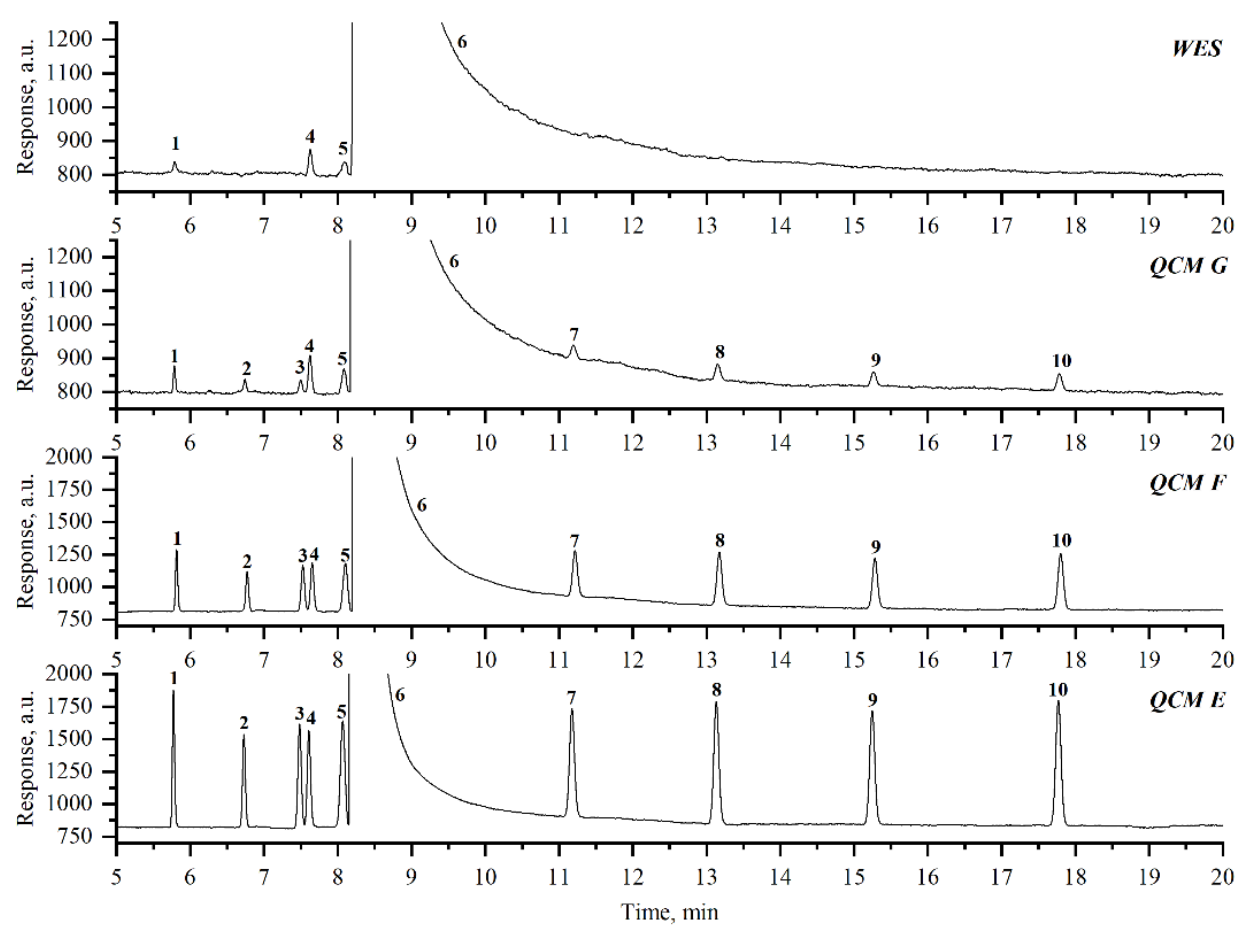

Figure 1. Typical chromatograms of WES and QCM G, F, E solutions. 1 - acetaldehyde, 2 - methyl acetate, 3 - ethyl acetate, 4 - methanol, 5 - propan-2-ol, 6 - ethanol, 7 - propan-1-ol, 8 2-methylpropan-1-ol, 9 - butan-1-ol, 10 - 3-methylbutan-1-ol

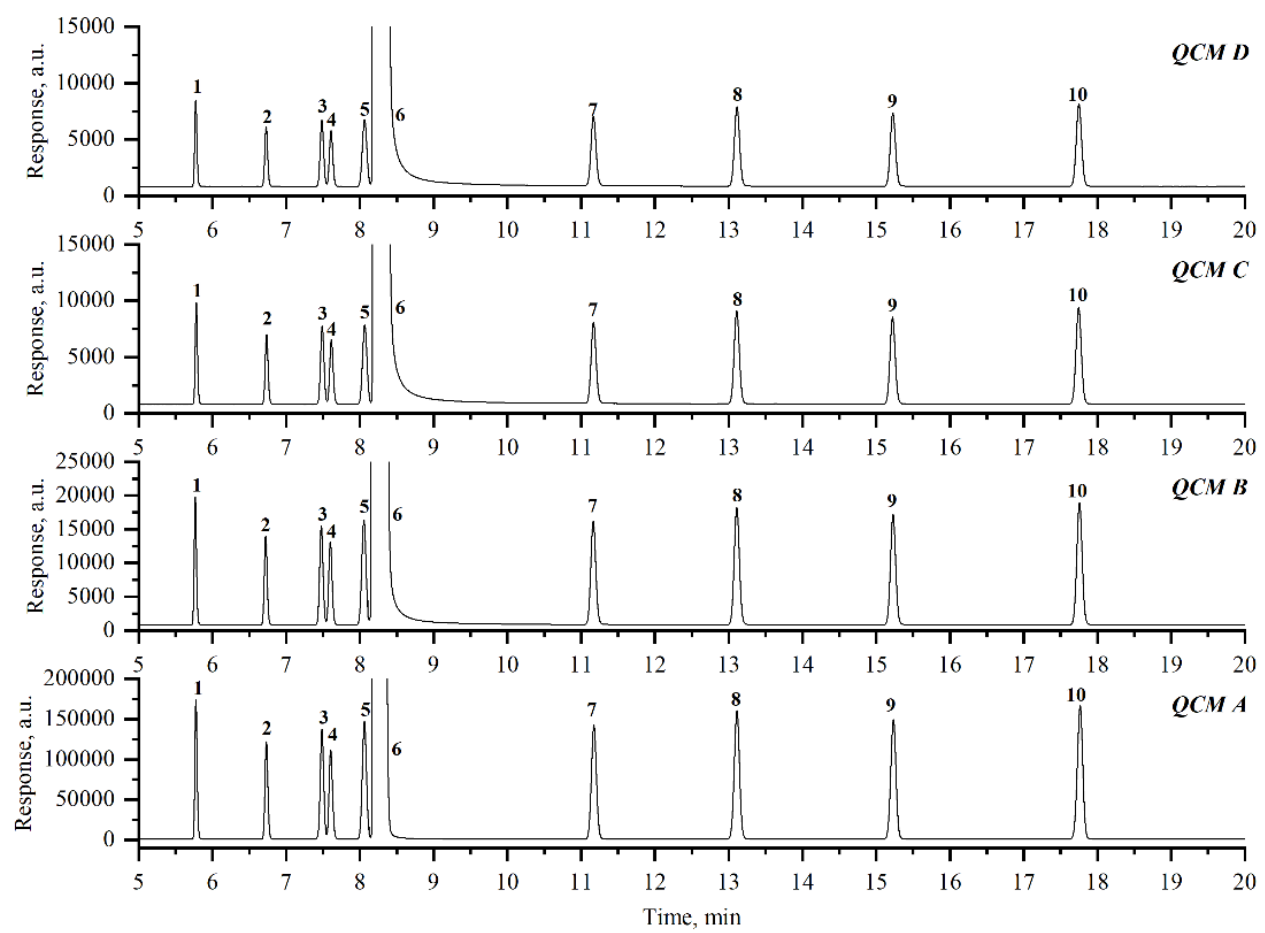

Figure 2. Typical chromatograms of QCM D, C, B and A solutions. 1 - acetaldehyde, 2 - methyl acetate, 3 - ethyl acetate, 4 - methanol, 5 - propan-2-ol, 6 - ethanol, 7 - propan-1-ol, 8 2-methylpropan-1-ol, 9 - butan-1-ol, 10 - 3-methylbutan-1-ol 
Development of a quality control material for the analysis

\subsection{Uncertainty Estimation}

The expanded uncertainty of QCM can be estimated according to the following formula [18]

$$
U_{Q C M}=k \cdot \sqrt{u_{c h a r}^{2}+u_{h o m}^{2}+u_{s t s}^{2}+u_{l t s}^{2}},
$$

where $k$ is the coverage factor, $k=2 ; u_{\text {char }}$ is standard uncertainty associated with a value assigned in a characterization study; $u_{\text {hom }}$ is standard uncertainty associated with potential between-unit heterogeneity; $u_{s t s}$ is standard uncertainty associated with the transport stability of material; $u_{l t s}$ is standard uncertainty associated with long-term stability of material.

The expected value of the relative expanded uncertainty of QCM $u_{Q C M}^{\exp }$ was no more than $4.5 \%$ for solution $\mathrm{G}$ and $3.0 \%$ for other solutions.

\subsection{Characterization of the $Q C M$}

The characterization of QCM was carried out by preparation procedure, according to the Technical Report 1/2007 [21], ISO/IEC GUIDE 98 [22] and EURACHEM/CITAC Guide [23]. The full description of estimation and calculation of $u_{\text {char }}$ for prepared solutions is performed in the item S.2 of Supplementary material and presented schematically in Figure 3.

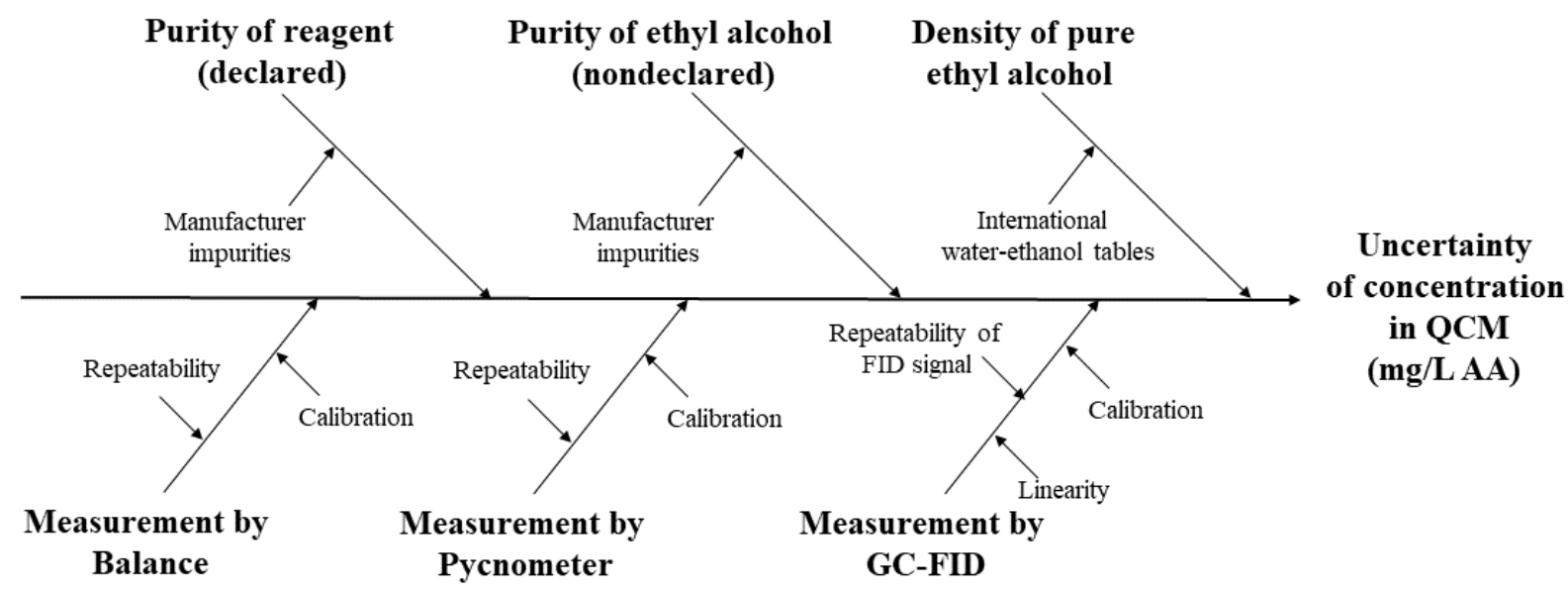

Figure 3. The general Fishbone diagram for the determination of uncertainty (associated with a value assigned in a characterization study) of analyte concentration in QCM

\subsection{Assessment of Homogeneity}

The homogeneity testing of QCM was carried out by a single primary method [5-10] according to the item 7 of ISO Guide 35 [18].

The packaging of QCM is $2 \mathrm{~mL}$ vials for autosampler in order to single use in analysis. Thus, QCM, prepared in a $100 \mathrm{~mL}$ volumetric flask, will be placed in vials and delivered to the user in this form. For this reason, the within-unit homogeneity was not estimated as unnecessary. The number of units, sampled for homogeneity study is 10 , according to the recommendations in item 7.1 of ISO Guide 35 [18]. A between-unit homogeneity study was conducted using the aforementioned GC-FID method based on the use of ethanol as an internal standard [4-9].

The statistical analysis of obtained results was carried out with Cochran's test, according to the item 7.3.3 of ISO 5725-2 [20] in order to check the homogeneity of the variances. The obtained results of measurements and testing with Cochran's test are shown in Table S.3.1 and Tables S.3.2 of Supplementary material, correspondingly.

The ANOVA analysis of variances was carried out for each QCM according to the item 7.7.4 of ISO Guide 35 [18] using MS Excel 2016. The results of ANOVA test of the homogeneity study are presented in Table S.3.3 of Supplementary material. 
Charapitsa et al., J. Chem.Metrol.15:2 (2021) 113-123

[18]

The standard uncertainty of homogeneity $u_{\text {hom }}$ was calculated according to the following formula

$$
u_{\text {hom }}=\sqrt{\frac{M S_{\text {within }}}{n_{0}} \cdot \sqrt{\frac{2}{v_{M S_{\text {within }}}}}},
$$

where $M S_{\text {within }}$ is the within-group variance; $n_{0}$ is number of observations per group, $n_{0}=2 ; v_{M S_{\text {within }}}$ is degree of freedom of the within-group variance, $v_{M S_{\text {within }}}=10$.

\subsection{Assessment of Stability}

The stability testing of QCM was carried out by according to the item 8 of ISO Guide 35 [18].

\subsubsection{Short-term Stability}

The short-term stability study was not carried out as unnecessary, according to the item 12 of ISO Guide 80 [4].

The storage temperature of QCMs should be strictly defined: $(5 \pm 4){ }^{\circ} \mathrm{C}$. Due to the fact, that the composition of the QCM is complicated (11 compounds: acetaldehyde, methyl acetate, ethyl acetate, methanol, propan-2-ol, propan-1-ol, 2-methylpropan-1-ol, butan-1-ol, 3-methylbutan-1-ol, ethanol and water) violation of the storage conditions will lead to the unsuitability of the solutions.

This can be explained by chemical processes in solutions of volatile compounds. In any case, chemical redox reactions will occur in such a solution when the recommended storage temperature is raised or lowered.

Acetaldehyde, as the most reactive compound in solution, is prone to polymerization reactions at low temperatures $\left(\leq 0^{\circ} \mathrm{C}\right)$ [24] and reduction at high temperatures $\left(\geq 30^{\circ} \mathrm{C}\right)$ [25,26]. The studies of degradation of acetaldehyde did not found any relationships between the reduction of acetaldehyde mass concentrations and storage temperature.

Another volatile compounds can be also undergone redox reactions at high temperatures in the presence of oxygen in the vial (ethanol to acetaldehyde or acetic acid, propan-2-ol to acetone) and other reactions (ethanol with acetaldehyde to 1,1-diethoxyethane, alcohols with acetic acid to ethyl ethers). Combination and esterification reactions are less likely than redox reactions, but can also occur.

Thus, it makes no sense to study the short-term stability of the QCM at temperatures above and below the recommended storage temperature, since the chemical reaction in solutions cannot be quantitatively described and it is obvious that the solution will be unusable.

The short-term stability of the similar solutions during transportation has been partially proven in a previous interlaboratory study of the method of analysis [8]. Water-ethanol solutions with a mass concentration of volatile compounds from 10 to $500 \mathrm{mg} / \mathrm{L}$ of AA, prepared by analogy with solutions in the current experiment, were delivered by air and land transport to 9 laboratories from 4 countries (Russia, Czech Republic, Turkey and Belarus). After transportation, the solutions had the same characteristics as after preparation.

\subsubsection{Long-term Stability}

The classical monitoring design was chosen for stability study according to the item 8.10.3.1 of ISO Guide 35 [18].

Stability studies were performed every 7 days for 6 months for solution $G$ (27 tests) and every 14 days for 6 months for other solutions (14 tests), stored at recommended temperature $(5 \pm 4){ }^{\circ} \mathrm{C}$.

The intermediate results of stability monitoring were estimated according to the condition [18] 
Development of a quality control material for the analysis

$$
\left|x_{Q C M}-x_{\text {mon }}\right| \leq k \cdot \sqrt{u_{Q C M}^{2}+u_{m o n}^{2}},
$$

where $x_{Q C M}$ is the mass concentration of the volatile compound in QCM, mg/L AA; $x_{m o n}$ is the mass concentration of the volatile compound in QCM, obtained by measuring monitoring point with formula (2), mg/L AA; $k$ is the coverage factor, $k=2 ; u_{Q C M}$ is the standard uncertainty, associated with the mass concentration of the volatile compound in QCM, mg/L AA; $u_{m o n}$ is the standard uncertainty, associated with the mass concentration of the volatile compound in QCM, obtained by measuring at monitoring point, $\mathrm{mg} / \mathrm{L}$ AA.

The standard uncertainties, associated with the mass concentration of the volatile compound in QCM $u_{Q C M}$ and associated with the mass concentration of the volatile compound in QCM $u_{\text {mon }}$ were calculated according to the following formula

$$
u_{Q C M}=u_{m o n}=\frac{u_{Q C M}^{\exp }}{2} .
$$

If the condition (3) was not met, the significance of instability would be confirmed.

The statistical analysis of obtained results was carried out with Cochran's and Grubbs' tests, according to the items 7.3.3 and 7.3.4 of ISO 5725-2 [20] correspondingly, in order to check the outliers. The obtained results of measurements and testing with Cochran's and Grubbs' tests are shown in Table S.4.1 and Table S.4.2 of Supplementary material, correspondingly. The results of the checking of condition (3) are presented in Table S.4.3 of Supplementary material.

In order to estimate the presence of a trend in the data, the method, described in the item B.3 of ISO Guide 35 [18] was used. An analysis of the slope was carried out on the results, assuming the linear regression, where $x$ is the storage time in days and $y$ is the mass concentration of the volatile compound in QCM in $\mathrm{mg} / \mathrm{L}$ AA (Figures 4-6).

The regression parameters $b_{1}$ and $b_{0}$ and their standard errors $s\left(b_{1}\right)$ and $s\left(b_{0}\right)$ were calculated according to the item B.3.2 of ISO Guide 35 [18].Inorder to estimate whether the slope significantly different from zero, a Student's test was carried out according to the item B 3.4 of ISO Guide 35 [18].

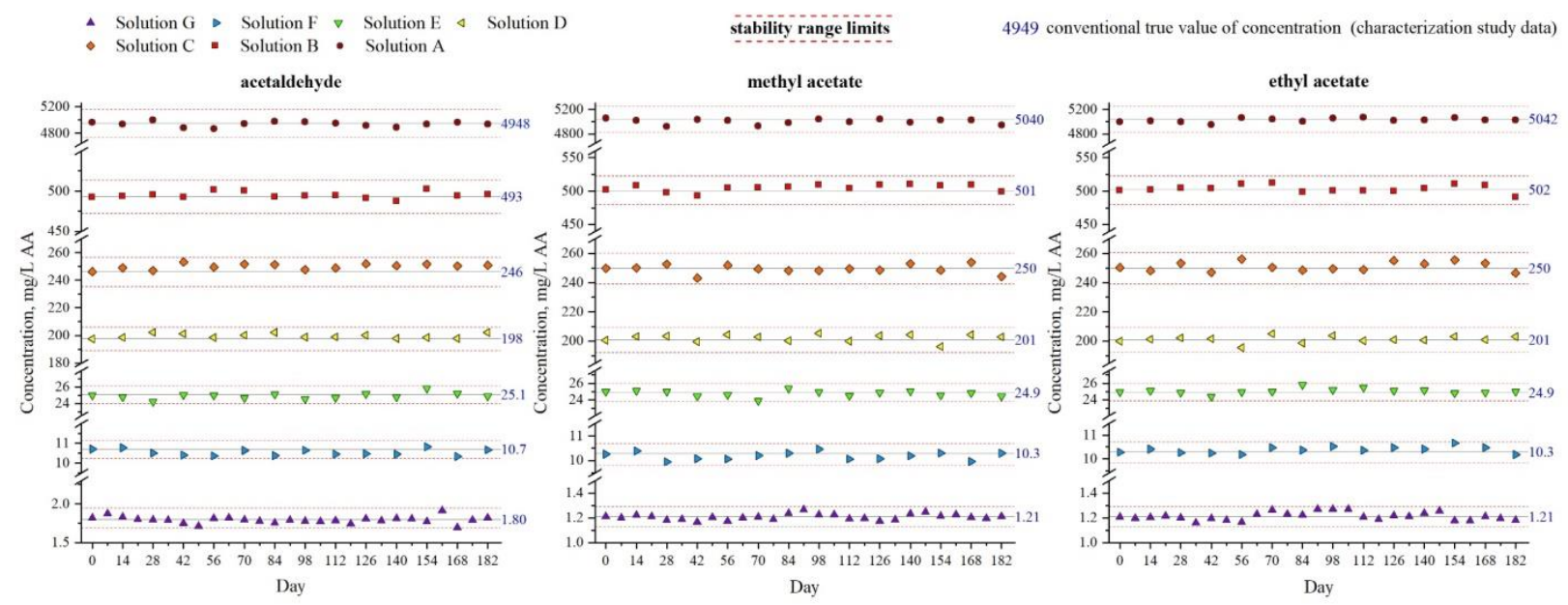

Figure 4. The stability monitoring results for acetaldehyde, methyl acetate and ethyl acetate 
Charapitsa et al., J. Chem.Metrol.15:2 (2021) 113-123

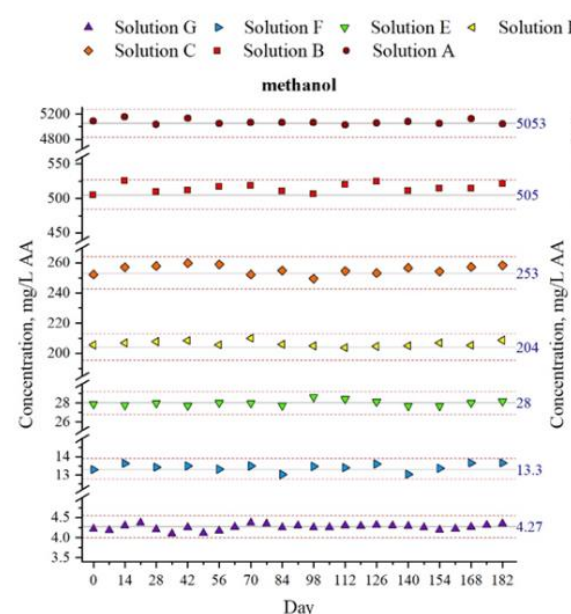

Day

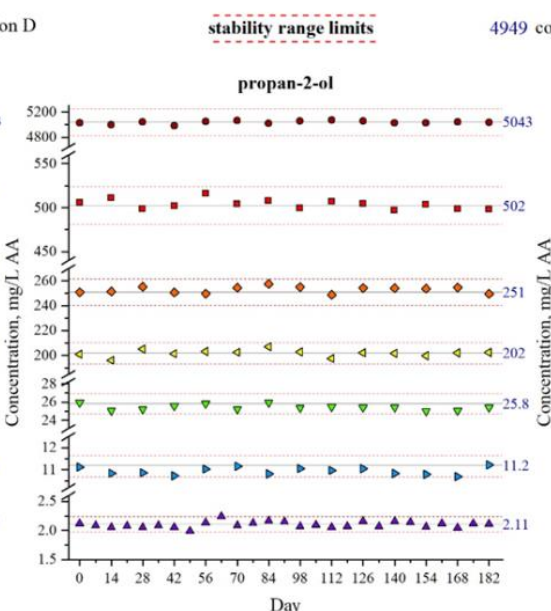

Day

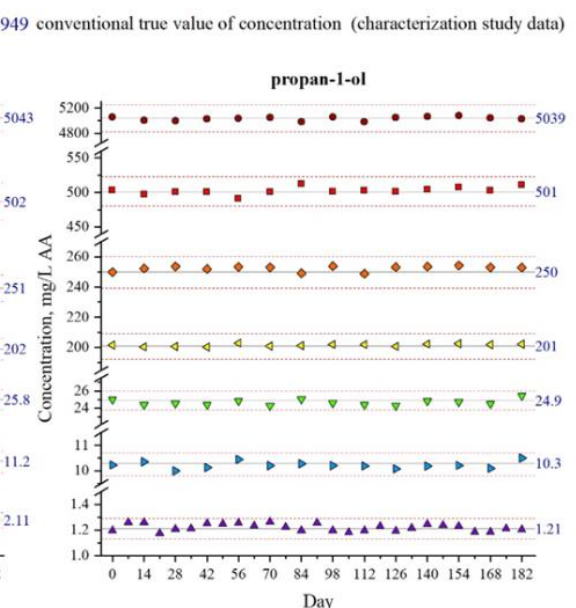

Day

Figure 5. The stability monitoring results for methanol, propan-2-ol, propan-1-ol

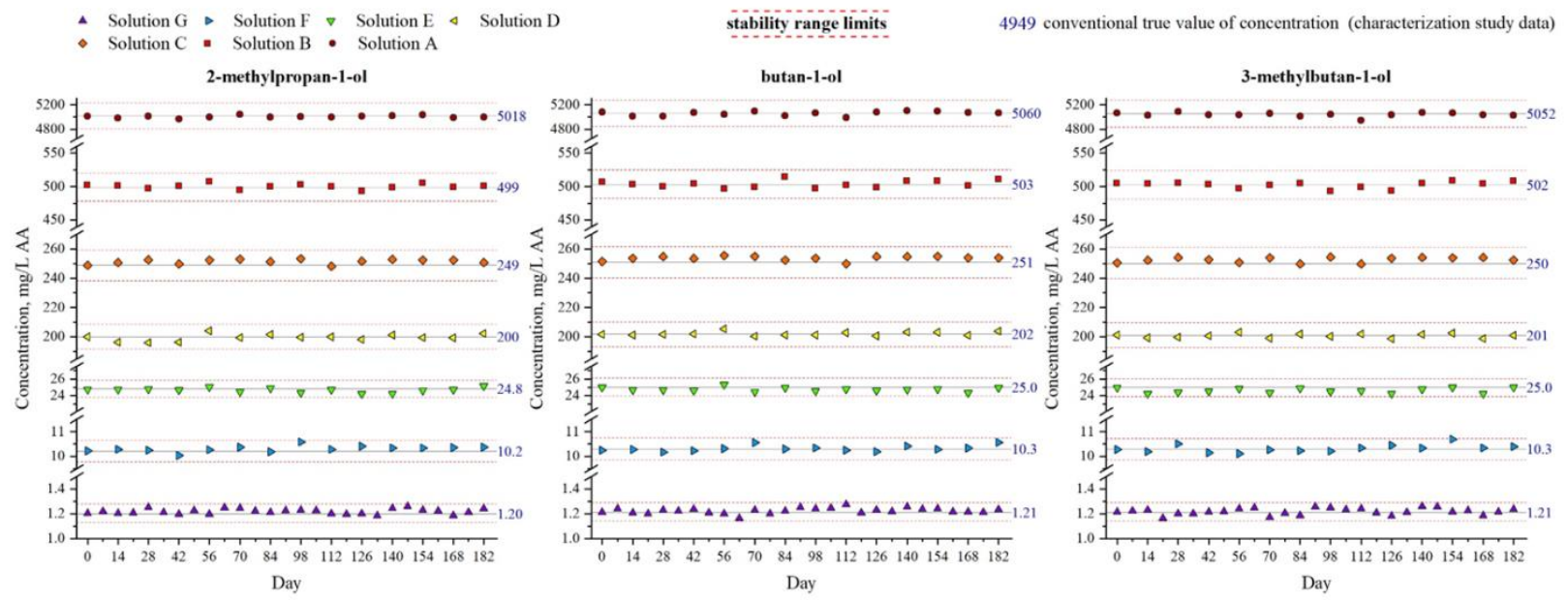

Figure 6. The stability monitoring results for 2-methylpropan-1-ol, butan-1-ol, 3-methylbutan-1-ol. Estimation was conducted by calculating of t-statistics according to the formula [18]

$$
t_{b_{1}}=\left|b_{1}\right| / s_{b_{1}},
$$

where $t_{b_{1}}$ is the critical value for estimation of significance of the slope.

If the obtained critical value for estimation of significance of the slope $t_{b_{1}}$ was less or equal, than the two-tailed critical value of Student's test for $n-2$ degrees of freedom at $95 \%$ level of confidence $t_{\text {crit }}$ ( $t_{c r i t}=2.06$ for solution $G$ and $t_{c r i t}=2.18$ for other solutions) the absence of a significant trend was proven. The results of calculations are shown in the Table S.4.4 of Supplementary material. formula

The standard uncertainty of long-term stability $\boldsymbol{u}_{l t s}$ was calculated according to the following

$$
u_{l t s}=s\left(b_{1}\right) \cdot t,
$$

where $t$ is the time of a long-term stability study, $t=182$ days ( 6 months). 
Development of a quality control material for the analysis

\section{Results and Discussion}

\subsection{Uncertainty Estimation}

Theresultsof characterization of prepared solutions showed, that developed algorithm of calculations of mass concentrations in WES allows to specify the values of calibration coefficients for acetaldehyde, methanol and propan-2-ol on $0.2,1.2$ and $0.3 \%$ relative, correspondingly (Table S.1.1 of Supplementary material). The official method for the analysis of volatile compounds in alcoholic beverages [10] involves the preparation of standard solutions for further analysis, but there is no method for assessing the mass concentrations of target volatile compounds in a water-ethanol solution for preparation. Thus, the calibration coefficient, obtained for the official method [11], may be incorrect.

The results of experimental study of the certification of a QCM for the analysis of volatile compounds in alcoholic beverages showed, that the calculated values of the relative expanded uncertainty were less, than planned (4.5\% for solution $G$ and $3.0 \%$ for other solutions).

The results of calculations of standard uncertainty associated with a value assigned in a characterization study; standard uncertainty associated with potential between-unit heterogeneity; standard uncertainty associated with long-term stability of material and the expanded uncertainty of QCM are shown in the Table 1.

Table 1. The results of calculations of the relative expanded uncertainty $(P=0.95, k=2)$ of $Q C M$

\begin{tabular}{|c|c|c|c|c|c|c|c|c|c|c|c|c|}
\hline \multirow[b]{2}{*}{$Q C M$} & \multicolumn{4}{|c|}{ acetaldehyde } & \multicolumn{4}{|c|}{ methyl acetate } & \multicolumn{4}{|c|}{ ethyl acetate } \\
\hline & $\begin{array}{c}u_{\text {char }}, \\
\%\end{array}$ & $\begin{array}{c}u_{\text {hom }} \\
\%\end{array}$ & $u_{l t s}, \%$ & $\begin{array}{c}U_{Q C M}, \\
\%\end{array}$ & $\begin{array}{c}u_{\text {char }}, \\
\%\end{array}$ & $\begin{array}{c}u_{\text {hom }} \\
\%\end{array}$ & $u_{l t s}, \%$ & $\begin{array}{c}U_{Q C M}, \\
\%\end{array}$ & $\begin{array}{c}u_{\text {char }}, \\
\%\end{array}$ & $\begin{array}{c}u_{\text {hom }} \\
\%\end{array}$ & $u_{l t s}, \%$ & $\begin{array}{c}U_{Q C M}, \\
\%\end{array}$ \\
\hline$A$ & 0.40 & 0.13 & 0.68 & 1.61 & 0.36 & 0.20 & 0.78 & 1.76 & 0.36 & 0.16 & 0.53 & 1.32 \\
\hline$B$ & 0.40 & 0.10 & 0.77 & 1.75 & 0.35 & 0.23 & 0.87 & 1.93 & 0.35 & 0.21 & 1.01 & 2.17 \\
\hline$C$ & 0.40 & 0.06 & 0.66 & 1.55 & 0.35 & 0.10 & 1.09 & 2.30 & 0.35 & 0.11 & 1.14 & 2.40 \\
\hline$D$ & 0.37 & 0.13 & 0.80 & 1.78 & 0.31 & 0.12 & 1.13 & 2.36 & 0.31 & 0.13 & 1.04 & 2.19 \\
\hline$E$ & 0.39 & 0.07 & 1.25 & 2.62 & 0.34 & 0.08 & 1.35 & 2.80 & 0.34 & 0.18 & 1.15 & 2.43 \\
\hline$F$ & 0.35 & 0.19 & 1.35 & 2.82 & 0.31 & 0.21 & 1.38 & 2.86 & 0.31 & 0.11 & 1.16 & 2.41 \\
\hline$G$ & 0.49 & 0.17 & 1.60 & 3.36 & 0.34 & 0.10 & 1.24 & 2.57 & 0.34 & 0.11 & 1.72 & 3.51 \\
\hline \multirow[b]{2}{*}{$Q C M$} & \multicolumn{4}{|c|}{ methanol } & \multicolumn{4}{|c|}{ propan-2-ol } & \multicolumn{4}{|c|}{ propan-1-ol } \\
\hline & $\begin{array}{c}u_{\text {char }}, \\
\%\end{array}$ & $\begin{array}{c}u_{\text {hom }}, \\
\%\end{array}$ & $u_{l t s}, \%$ & $\begin{array}{c}U_{Q C M}, \\
\%\end{array}$ & $\begin{array}{c}u_{\text {char }}, \\
\%\end{array}$ & $\begin{array}{c}u_{\text {hom }}, \\
\%\end{array}$ & $u_{l t s}, \%$ & $\begin{array}{c}U_{Q C M}, \\
\%\end{array}$ & $\begin{array}{c}u_{\text {char }}, \\
\%\end{array}$ & $\begin{array}{c}u_{\text {hom }} \\
\%\end{array}$ & $u_{l t s}, \%$ & $\begin{array}{c}U_{Q C M}, \\
\%\end{array}$ \\
\hline $\bar{A}$ & 0.35 & 0.03 & 0.64 & 1.47 & 0.35 & 0.07 & 0.43 & 1.13 & 0.35 & 0.04 & 0.52 & 1.26 \\
\hline$B$ & 0.35 & 0.07 & 1.11 & 2.33 & 0.35 & 0.07 & 0.86 & 1.86 & 0.35 & 0.04 & 0.81 & 1.77 \\
\hline$C$ & 0.35 & 0.01 & 1.06 & 2.23 & 0.35 & 0.04 & 0.95 & 2.03 & 0.35 & 0.01 & 0.61 & 1.41 \\
\hline$D$ & 0.31 & 0.06 & 0.78 & 1.67 & 0.31 & 0.11 & 1.20 & 2.50 & 0.31 & 0.04 & 0.33 & 0.91 \\
\hline$E$ & 0.33 & 0.07 & 0.88 & 1.89 & 0.33 & 0.08 & 1.01 & 2.14 & 0.34 & 0.04 & 1.18 & 2.45 \\
\hline$F$ & 0.36 & 0.11 & 1.36 & 2.82 & 0.30 & 0.15 & 1.33 & 2.75 & 0.31 & 0.08 & 1.18 & 2.44 \\
\hline G & 0.87 & 0.07 & 1.02 & 2.68 & 0.55 & 0.14 & 1.56 & 3.33 & 0.34 & 0.14 & 1.43 & 2.95 \\
\hline \multirow[b]{2}{*}{$Q C M$} & \multicolumn{4}{|c|}{ 2-methylpropan-1-ol } & \multicolumn{4}{|c|}{ butan-1-ol } & \multicolumn{4}{|c|}{ 3-methylbutan-1-ol } \\
\hline & $\begin{array}{c}u_{\text {char }}, \\
\%\end{array}$ & $\begin{array}{c}u_{\text {hom }}, \\
\%\end{array}$ & $u_{l t s}, \%$ & $\begin{array}{c}U_{Q C M}, \\
\%\end{array}$ & $\begin{array}{c}u_{\text {char }}, \\
\%\end{array}$ & $\begin{array}{c}u_{\text {hom }}, \\
\%\end{array}$ & $u_{l t s}, \%$ & $\begin{array}{c}U_{Q C M}, \\
\%\end{array}$ & $\begin{array}{c}u_{\text {char }}, \\
\%\end{array}$ & $\begin{array}{c}u_{\text {hom }} \\
\%\end{array}$ & $u_{l t s}, \%$ & $\begin{array}{c}U_{Q C M}, \\
\%\end{array}$ \\
\hline$A$ & 0.39 & 0.05 & 0.36 & 1.06 & 0.35 & 0.05 & 0.59 & 1.38 & 0.38 & 0.09 & 0.58 & 1.39 \\
\hline$B$ & 0.38 & 0.06 & 0.68 & 1.57 & 0.35 & 0.03 & 0.93 & 1.99 & 0.38 & 0.07 & 0.87 & 1.90 \\
\hline$C$ & 0.38 & 0.03 & 0.56 & 1.36 & 0.35 & 0.01 & 0.54 & 1.29 & 0.38 & 0.02 & 0.59 & 1.40 \\
\hline$D$ & 0.35 & 0.06 & 0.95 & 2.03 & 0.31 & 0.03 & 0.62 & 1.39 & 0.34 & 0.03 & 0.63 & 1.43 \\
\hline$E$ & 0.38 & 0.07 & 0.98 & 2.10 & 0.34 & 0.04 & 0.92 & 1.97 & 0.37 & 0.06 & 1.08 & 2.28 \\
\hline$F$ & 0.35 & 0.15 & 0.95 & 2.05 & 0.31 & 0.09 & 0.94 & 1.99 & 0.34 & 0.11 & 1.18 & 2.48 \\
\hline$G$ & 0.38 & 0.13 & 1.10 & 2.34 & 0.34 & 0.07 & 1.16 & 2.43 & 0.37 & 0.08 & 1.39 & 2.87 \\
\hline
\end{tabular}

The ANOVA analysis of the results, obtained during the study of the homogeneity of solutions, showed satisfactory results - the approach for preparation and pouring into individual vials of solutions allows to achieve high homogeneity of samples and carry out a one-time analysis without any manual sampling.

The results of long-term stability study showed the highest values of relative uncertainty of longterm stability study for acetaldehyde (1.6\%), ethyl acetate $(1.7 \%)$ in solution $\mathrm{G}$ compared to other 
Charapitsa et al., J. Chem.Metrol.15:2 (2021) 113-123

volatiles. This fact can be explained by abovementioned probable ongoing chemical processes. Acetaldehyde can be formed from ethanol during oxidation in the presence of oxygen remaining in the vial when closed and at the same time convert to 1,1-diethoxyethane or acetic acid. Ethyl acetate can be produced as a result of the reaction of ethanol and acetic acid formed. Also, possible product of side reactions in solution -1,1-diethoxyethane has retention time is very close to retention time of ethyl acetate (features of the GC column used). Thus, 1,1-diethoxyethane formation could increase the peak of ethyl acetate. Further observations showed that for most volatile compounds, the relative uncertainty associated with stability gradually decreased, respectively, with an increase of the mass concentration of volatiles in solutions.

\section{Conclusions}

The developed QCMs can be useful for analytical laboratories performing routine analysis of volatile compounds in alcoholic beverages. A review of RM and CRM offers for the analysis of alcoholic beverages showed the absence of such a product on the market. The research results show that these QCMs can be studied and certified as CRMs: the expanded relative uncertainty of the QCM does not exceed $4.5 \%$, and the long-term stability is proved for 6 months.

During the study, a detailed description of the algorithm for accounting for impurities in ethyl alcohol-rectified and the assessment of the associated uncertainty was proposed and described in additional materials. The results showed that the developed algorithm for calculating the mass concentrations of analytes makes it possible to refine the values of the calibration coefficients and increase the accuracy of the analysis.

\section{Acknowledgements}

The study is part of Lidia Sobolenko's Ph.D. thesis.

\section{Supporting Information}

Supporting information accompanies this paper on http://www.acgpubs.org/journal/ journalof-chemical-metrology

\section{ORCID}

Siarhei Charapitsa:0000-0001-9657-1948

Svetlana Sytova: 0000-0002-2476-9979

Anton Kavalenka: 0000-0002-0320-2092

Lidia Sobolenko: 0000-0001-5066-7194

Yauheni Shauchenka: 0000-0001-9893-7210

Nikolai Kostyuk 0000-0003-2709-8047

Mikhail Zayats: 0000-0002-8400-6359

Vladimir Egorov: 0000-0001-9414-0423

Sergey Leschev: 0000-0001-5378-1718

Ina Melsitova:0000-0003-0930-8530

Siarhei Vetokhin: 0000-0002-8613-731X

Natalia Zayats 0000-0001-9243-6968

\section{References}

[1] Eurachem Guide: The Fitness for Purpose of Analytical Methods - A Laboratory Guide to Method Validation and Related Topics, Eurachem (2014).

[2] Catalog of Beverage reference materials (2021)https://www.lgcstandards.com/ES/en/Food-and-Beverage/Beveragereference-materials/cat/279604Accessed 01 November 2021.

[3] Catalog of Beverage reference materials: Whisky Congeners. (2021)https://www.lgcstandards.com/GB/en/WhiskyCongeners/p/LGC5100 Accessed 01 November 2021. 
Development of a quality control material for the analysis

[4] ISO Guide 80 (2014). Guidance for the in-house preparation of quality control materials (QCMs).

[5] Eurasian Patent № 036994 (2021)https://www.eapo.org/en/patents/reestr/patent.php?id=36994Accessed 01 November 2021.

[6] S. Charapitsa, S. Sytova, A. Korban, N. Boyarin, I. Shestakovich and R. Čabala (2018). The establishment of metrological characteristics of the method "Ethanol as Internal Standard" for the direct determination of volatile compounds in alcoholic products, J. Chem. Metrol. 12 (1), 59-69.

[7] S. V.Charapitsa, S. N.Sytova, A. L.Korban and L. N. Sobolenko (2019). Single-laboratory validation of a gas chromatographic method of direct determination of volatile compounds in spirit drinks: Need for an improved interlaboratory study, J. AOAC Int. 102, 669-672.

[8] S. Charapitsa, S. Sytova, A. Korban, L. Sobolenko, V. Egorov, S. Leschev, M. Zakharov, R. Čabala, R. Busarova, I. Shestakovich, A. Tolstouhova, S. Ondrousek,J. Vavra, M. Yilmaztekin and T. Cabaroglu (2019). Interlaboratory study of ethanol usage as an internal standard in direct determination of volatile compounds in alcoholic products, $B I O \mathrm{Web}$ Conf. 15, 1-8.

[9] S. Charapitsa, S. Sytova, A. Kavalenka, L. Sobolenko, N. Kostyuk, V. Egorov, S. Leschev, S. Vetokhin and N. Zayats (2021). The study of the matrix effect on the method of direct determination of volatile compounds in a wide range of alcoholic beverages, Food Cont. 120, 107528.

[10] S. Charapitsa, S. Sytova, A. Kavalenka, L. Sobolenko, Y. Shauchenka, N. Kostyuk, V. Egorov, S. Leschev, S. Vetokhin, N. Zayats, S. Tsimbalaev and A. Kolesnov (2021). The method for direct gas chromatographic determination of acetaldehyde, methanol, and other volatiles using ethanol as a reference substance: application for a wide range of alcoholic beverages, Food Anal. Method. 14, 2088-2100.

[11] Commission regulation (EC) No 2870/2000 laying down Community reference methods for the analysis of spirits drinks (2000).

[12] AOAC Official Method 972.11 (2005). Methanol in distilled liquors. Gas chromatographic method. Gaithersburg, MD, USA, AOAC International.

[13] GB/T 11858 (2008). Vodka. Beijing: National Standards of People's Republic of China.

[14] BIS IS 3752: 2005 (2009). Alcoholic drinks - Methods of test. New Delhi: Bureau of Indian Standards.

[15] NOM-199-SCFI (2017) Bebidas alcohólicas-Denominación, especificaciones fisicoquímicas, información comercial y métodos de prueba: NORMA Oficial Mexicana.

[16] ASTM D4307 - 17 (2017). Standard practice for preparation of liquid blends for use as analytical standards.

[17] ISO/IEC 17025 (2017). General requirements for the competence of testing and calibration laboratories.

[18] ISO Guide 35 (2017). Reference materials - Guidance for characterization and assessment of homogeneity and stability.

[19] ISO 17034 (2016). General requirements for the competence of reference material producers.

[20] ISO 5725-2 (2019). Accuracy (trueness and precision) of measurement methods and results - Part 2: Basic method for the determination of repeatability and reproducibility of a standard measurement method.

[21] EUROLAB Technical Report 1/2007 (2007). Measurement uncertainty revisited: Alternative approaches to uncertainty evaluation.

[22] ISO/IEC GUIDE 98-3 (2008). Uncertainty of measurement — Part 3: Guide to the expression of uncertainty in measurement (GUM:1995).

[23] S. L. R. Ellison and A. Williams (2012). Eurachem/CITAC guide: Quantifying uncertainty in analytical measurement, Third edition.

[24] J. C. Bevington and R. G. W. Norrish (1949). The polymerization of acetaldehyde at low temperatures, Proc. R. Soc. London. Ser. A. Math. Phys. Sci. 1046, 363-378.

[25] M. Różański, K. Pielech-Przybylska and M. Balcerek (2020). Influence of alcohol content and storage conditions on the physicochemical stability of spirit drinks, Foods $\mathbf{9}, 1264$.

[26] G. Han, M. R. Webb and A. L. Waterhouse (2019) Acetaldehyde reactions during wine bottle storage, Food Chem. 290, 208-215.

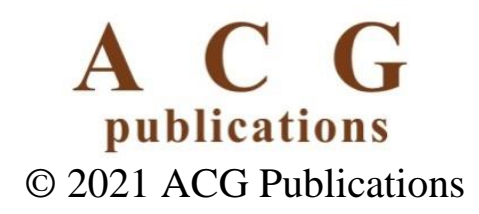

